\title{
Response of high-risk of recurrence/progression bladder tumours expressing sialyl-Tn and sialyl-6-T to BCG immunotherapy
}

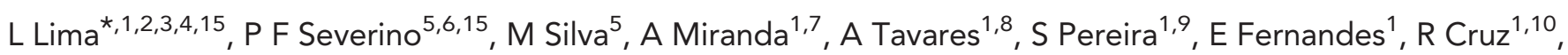
T Amaro ${ }^{11}$, C A Reis ${ }^{2,12,13}$, F Dall'Olio ${ }^{6}$, F Amado ${ }^{7}$, P A Videira ${ }^{5}$, L Santos ${ }^{1,9,14}$ and J A Ferreira ${ }^{*, 1,7}$

${ }^{1}$ Experimental Pathology and Therapeutics Group, Portuguese Institute of Oncology, Porto, Portugal; ${ }^{2}$ Institute of Biomedical Sciences of Abel Salazar, University of Porto, Porto, Portugal; ${ }^{3}$ Nucleo de Investigação em Farmácia-Centro de Investigação em Saúde e Ambiente (CISA), Health School of the Polytechnic Institute of Porto, Porto, Portugal; ${ }^{4}$ LPCC, Research DepartmentPortuguese League Against Cancer (NRNorte), Porto, Portugal; ${ }^{5}$ CEDOC, Department of Immunology, Faculdade de Ciências Médicas, FCM, Universidade Nova de Lisboa, Lisboa, Portugal; ${ }^{6}$ Department of Experimental, Clinical and Specialty Medicine (DIMES), University of Bologna, Bologna, Italy; ${ }^{7}$ QOPNA, Mass Spectrometry Center, Department of Chemistry, University of Aveiro, Aveiro, Portugal; ${ }^{8}$ Department of Pathology, Portuguese Institute of Oncology, Porto, Portugal; ${ }^{9}$ Health School of University of Fernando Pessoa, Porto, Portugal; ${ }^{10}$ Department of Urology, Portuguese Institute of Oncology, Porto, Portugal; ${ }^{11}$ Department of Pathology, Hospital Pedro Hispano, Matosinhos, Portugal; ${ }^{12}$ Institute of Molecular Pathology and Immunology of the University of Porto (IPATIMUP), Porto, Portugal; ${ }^{13}$ Medical Faculty, University of Porto, Porto, Portugal and ${ }^{14}$ Department of Surgical Oncology, Portuguese Institute of Oncology, Porto, Portugal

Background: High risk of recurrence/progression bladder tumours is treated with Bacillus Calmette-Guérin (BCG) immunotherapy after complete resection of the tumour. Approximately $75 \%$ of these tumours express the uncommon carbohydrate antigen sialyl-Tn (Tn), a surrogate biomarker of tumour aggressiveness. Such changes in the glycosylation of cell-surface proteins influence tumour microenvironment and immune responses that may modulate treatment outcome and the course of disease. The aim of this work is to determine the efficiency of BCG immunotherapy against tumours expressing sTn and sTn-related antigen sialyl-6-T (s6T).

Methods: In a retrospective design, 94 tumours from patients treated with BCG were screened for sTn and s6T expression. In vitro studies were conducted to determine the interaction of BCG with high-grade bladder cancer cell line overexpressing sTn.

Results: From the 94 cases evaluated, 36 had recurrence after BCG treatment (38.3\%). Treatment outcome was influenced by age over 65 years $(H R=2.668 ;(1.344-5.254) ; P=0.005)$, maintenance schedule $(H R=0.480 ;(0.246-0.936) ; P=0.031)$ and multifocallity $(H R=2.065 ;(1.033-4.126) ; P=0.040)$. sTn or s6T expression was associated with $B C G$ response $(P=0.024 ; P<0.0001)$ and with increased recurrence-free survival $(P=0.001)$. Multivariate analyses showed that sTn and/or s6T were independent predictive markers of recurrence after $B C G$ immunotherapy $(H R=0.296 ;(0.148-0.594) ; P=0.001)$. In vitro studies demonstrated higher adhesion and internalisation of the bacillus to cells expressing sTn, promoting cell death.

Conclusion: s6T is described for the first time in bladder tumours. Our data strongly suggest that BCG immunotherapy is efficient against sTn- and s6T-positive tumours. Furthermore, sTn and s6T expression are independent predictive markers of BCG treatment response and may be useful in the identification of patients who could benefit more from this immunotherapy.

${ }^{*}$ Correspondence: Dr L Lima or Professor JA Ferreira; E-mail: luis14lima@gmail.com or alexandrecastroferreira@gmail.com
${ }^{15}$ These authors contributed equally to this work.

Received 23 May 2013; revised 15 August 2013; accepted 26 August 2013; published online 24 September 2013

(c) 2013 Cancer Research UK. All rights reserved 0007-0920/13 
Bladder cancer is the fifth most common cancer in Western society (van Rhijn et al, 2009), with the highest recurrence rate among solid tumours and poor prognosis when the tumour invades the muscularis propia (Babjuk et al, 2011). To reduce the risk of recurrence and progression to muscle invasion, non-muscle invasive high-grade tumours, multifocal and recurrent lesions are submitted to intravesical instillations with live attenuated Bacillus Calmette-Guérin (BCG) after complete transurethral resection of bladder tumour (TURBT; Babjuk et al, 2011). Although the management of the disease has significantly improved with this therapeutics, $30-40 \%$ of the patients relapse and approximately $15 \%$ progress to muscle invasive tumours (Palou Redorta, 2006). Predicting patients who could be best served by an alternative treatment or early cystectomy, would avoid progression, reduce disease charge and decrease health expenses. It is consensual that the integration of multiple biomarkers may hold predictive value; still such biomarker panel remains to be established (Lima et al, 2012; Zuiverloon et al, 2012).

The exact mechanism by which BCG mediates anti-bladder cancer immunity remains elusive (Alexandroff et al, 2010). However, the capability of the bacillus to recognise and efficiently bind to tumour cells has a determinant role in the therapeutics outcome (Alexandroff et al, 2010). The bacillus is then internalised triggering tumour cell apoptosis or host adaptive immune responses (Becich et al, 1991; Ratliff, 1992). The bacterial adhesion, fibronectin attachment protein (FAP), was recognised as the main factor mediating BCG attachment and internalisation by bladder tumour cells (Sinn et al, 2008; Alexandroff et al, 2010). FAP binds to $\alpha 5 \beta 1$ integrins expressed by tumour cells via a fibronectin bridge and to be responsible for the uptake of BCG-fibronectin-integrin complexes (Sinn et al, 2008; Alexandroff et al, 2010).

Malignant transformations may be accompanied by a premature stop in the $O$-glycosylation of proteins by sialylation, originating the sialyl-Tn (sTn, Neu5Ac $\alpha 2-6$ GalNAc $\alpha-O-S e r / T h r)$ and sialyl6-T antigens (s6T, Gal $\beta 1-3(\mathrm{Neu} 5 \mathrm{Ac} \alpha 2-6) \mathrm{GalNAc} \alpha-\mathrm{O}-\mathrm{Ser} / \mathrm{Th}$; Dall'Olio et al, 2012). We recently reported that approximately $75 \%$ of high-grade bladder tumours, presenting elevated proliferation indexes and high risk of recurrence/progression expressed sTn (Ferreira et al, 2013). sTn expression enhanced the invasive capability of bladder cancer cells and was considered a surrogate biomarker of tumour aggressiveness (Ferreira et al, 2013). Hence, efficient therapies to manage these tumours are needed to avoid disease progression and poor outcomes.

sTn expression is known to interfere with cell-cell adhesion, cell-matrix interaction, including integrin-fibronectin binding, modulate cell morphology (Clement et al, 2004; Julien et al, 2006; Pinho et al, 2007) and immune responses (Gilewski et al, 2007; Julien et al, 2009; Takamiya et al, 2013). Thus, we hypothesise it may modulate BCG attachment to tumour cells and/or immune response and consequently influence BCG immunotherapy outcome. sTn is also a biomarker of concomitant molecular alterations that may further determine the tumour behaviour (Ohno et al, 2006). As such, this work is devoted to evaluating the response of sTn-positive bladder tumours to BCG immunotherapy. The sTn structurally related antigen was also evaluated for the first time in the context of bladder cancer.

\section{MATERIALS AND METHODS}

Patient cohort. This study was performed in a retrospective series of 94 cases with high-risk non-muscle invasive bladder cancer. Patients were treated with TURBT and then submitted to BCG immunotherapy in the Portuguese Oncology Institute of Porto, between 1998 and 2006. No second-look TURBT was performed, although the majority of the samples had muscularis propria tumour free. All received intravesical instillation of BCG for 6 consecutive weeks (induction BCG scheme, iBCG) and 56.4\% were submitted to maintenance BCG schedule (iBCG + maintenance protocol with two weekly instillations every 3 months during 2 years, $\mathrm{mBCG})$. The iBCG group includes patients treated before the European Association of Urology guidelines recommending the mBCG (Oosterlinck et al, 2006) scheme and patients showing significant intolerance to long BCG treatment.

The male/female sex ratio was of 78:16. The patients were followed every 3 months for the first year, every 6 months for the second year and every 12 months thereafter by cystoscopy and urine cytology. Recurrence was defined as the appearance of a tumour once the treatment has begun, with at least one tumourfree cystoscopy and cytology in-between. These recurrences were also available for study. The non-responders were defined as patients submitted to BCG treatment with tumour recurrence. Finally, recurrence-free survival (RFS) was defined as the period of time between the beginning of treatment and recurrence or the most recent tumour-free cystoscopy and cytology. All procedures were performed after patient's informed consent and approved by the Ethics Committee of IPO-Porto. All clinicopathological information was obtained from patients' clinical records. All tumour samples were revised by a pathologist, regarding 2004 WHO grading criteria.

Expression of STn in bladder tumours. Formalin-fixed paraffinembedded tissue sections were screened for sTn by immunohistochemistry using the avidin/biotin peroxidase method, as described by Ferreira et al (2013). sTn expression was evaluated with anti-sTn mouse monoclonal antibody clone TKH2 (Ferreira et al, 2013). The s6T antigen was evaluated in sTn-negative tumours using the same antibody, after treatment with a recombinant $\beta$-(1-3)-galactosidase from Xanthomonas campestris (R\&D systems, Minneapollis, $\mathrm{MN}$, USA) for $1 \mathrm{~h}$ at $37^{\circ} \mathrm{C}$. This enzyme removes the O-3-linked Gal residues exposing the sTn antigen (Figure 1A).

Both antigens were assessed double-blindly by three independent observers. Upon disagreement, the slides were reviewed, until a consensus was reached. Tumours were classified as positive when immunoreactivity of anti-sTn TKH2 antibody was observed.

Structural assignments were validated by a combination of enzymatic treatments. For sTn, positive tissues were first treated with a $\alpha$-neuraminidase from Clostridium perfringens (SigmaAldrich, St Louis, MO, USA) for $2 \mathrm{~h}$ at $37^{\circ} \mathrm{C}$ to remove the sialic acid and then screened for sTn expression. For s6T, positive tissues were primarily incubated with the $\beta$-(1-3)-galactosidase, followed by incubation with the neuraminidase. The absence or decrease in immunoreactivity of $\mathrm{TKH} 2$ monoclonal antibody confirmed the presence of these structures.

\section{Adhesion and internalisation of BCG to bladder cancer cell line}

Cell lines culture. The human bladder cancer cell line MCR and the transduced variants of MCR (MCRnc and MCRsTn ${ }^{+}$) were grown as described by Videira et al (2009). The MCRsTn ${ }^{+}$cell line results from the stable transduction of MCR cells with a lentivirus expressing the coding region of the human ST6GalNAc.I gene, the enzyme responsible by the biosynthesis of sTn (Ferreira et al, 2013). The MCRnc cell line, not expressing sTn, was used as control (Ferreira et al, 2013).

Bacterial strain and labelling. BCG strain RIVM (Medac, Hamburg, Germany) was used in this study. Briefly, $10^{8}$ viable BCG cells were labelled with $10 \mu \mathrm{g}$ fluorescein isothiocyanate (FITC; Invitrogen, Carlsbad, CA, USA) in $1 \mathrm{ml}$ of $50 \mathrm{~mm}$ sodium carbonate buffer ( $\mathrm{pH}$ 9.2) for $30 \mathrm{~min}$ at $20^{\circ} \mathrm{C}$. The labelled bacteria (BCG-FITC) were washed three times with PBS containing $0.05 \%$ of Tween- 80 (Sigma-Aldrich) and centrifuged for $10 \mathrm{~min}$ at $13.000 \mathrm{~g}$ to remove excess FITC. 
A

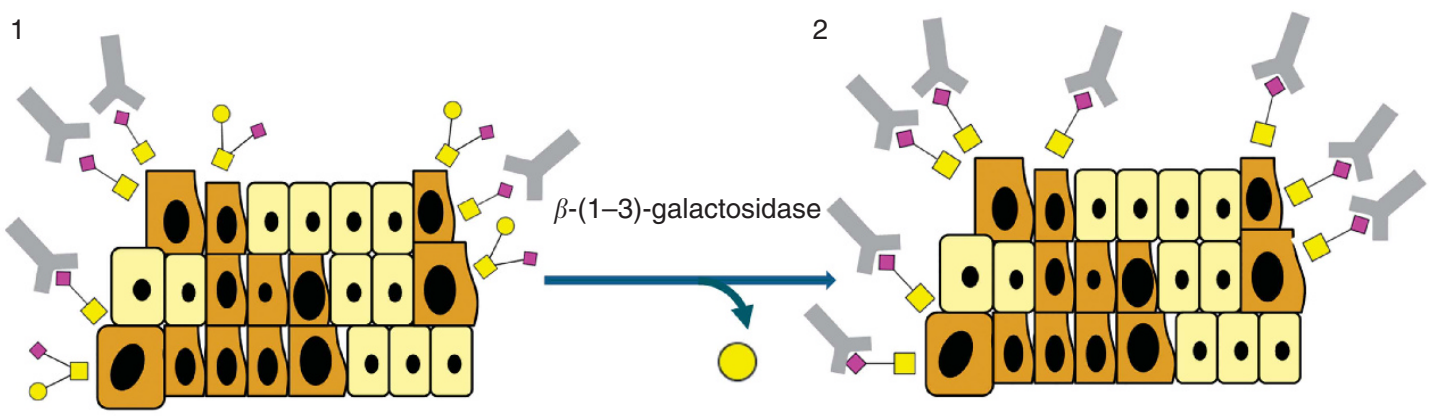

GaINAc

STn (Neu5Ac $\alpha 2-6$ GalNAc $\alpha$-O-Ser/Thr)

Gal

Neu5Ac (sialic acid)

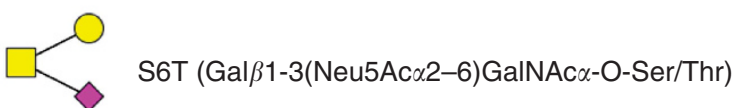

Anti-STn MoAb TKH2

0 Urothelial cell Tumour cell

B

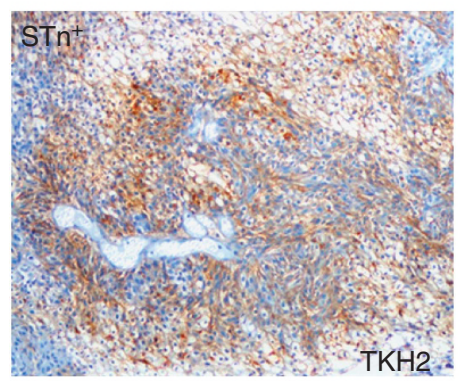

C

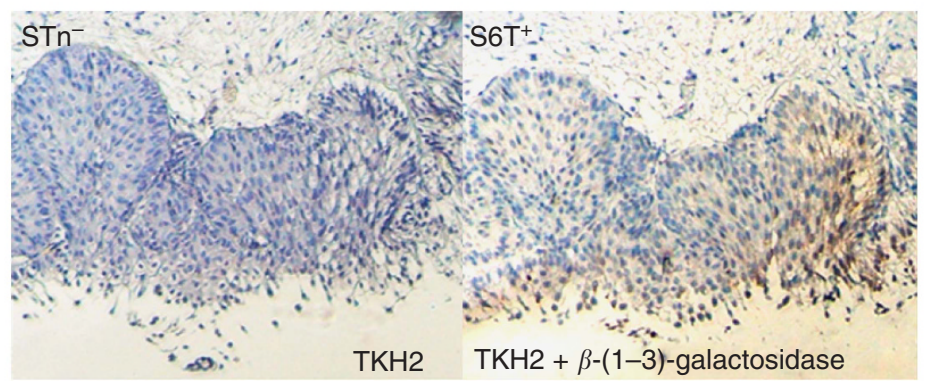

Figure 1. Expression of sTn and s6T in bladder tumours. Schematic representation of a bladder tumour expressing sTn and s6T antigens (A). Urothelial cell-surface glycoproteins present more or less elongated O-glycan chains often terminated with ABO and/or Lewis blood group determinants (not represented). Conversely, some malignant cells express the sTn and s6T (STn + Gal residue) antigens that result from a premature stop in the biosynthesis of O-glycans (A). The sTn, but not the s6T antigen, can be recognised by mouse monoclonal antibody TKH2 (A1). The digestion of the FFPE sections with a $\beta$-(1-3)-galactosidase removes the Gal residue from s6T allowing detection by TKH2 (A2). Bladder tumour expressing the sTn antigen (B). Bladder tumour expressing the s6T antigen but not sTn (C). The FFPE tissue was positive for sTn only after digestion of the FFPE tissue with a $\beta$-(1-3)-galactosidase. This is the first report on s6T antigen expression in bladder tumours.

BCG adhesion and internalisation assay. MCR cells were plated into 24 -well plates at $0.2 \times 10^{6}$ cell per well. At confluence, cells were washed and BCG-FTIC was added to the cultures at a ratio of 10:1 (BCG/cells). After 2, 6 or $24 \mathrm{~h}$ incubation time, the cells were gently washed to remove the excess BCG, harvested and centrifuged at $350 \mathrm{~g}$ for $5 \mathrm{~min}$. In order to differentiate between internalised and surface-bound BCG, trypan blue was added to quench surface-attached fluorescence bacteria. Flow cytometry was performed on a FACSCalibur (BD Biosciences, San Jose, CA, USA) and data were analysed using the Flowing v2.4 software (Turku Center for Biotechnology, Turku, Finland).

Estimation of cell viability after exposure to BCG. The influence of BCG treatment on MCR cell viability after the $24 \mathrm{~h}$ of exposure was assessed through the visualisation of morphologic changes by flow cytometry. Dot plots of forward-angle light scatter (FSc) vs side-angle light scatter (SSc) of MCR cells before and after exposure to BCG were analysed using the Flowing v2.4 software (Turku Center for Biotechnology).
For a shorter period of time of BCG exposure (6h), apoptotic status of cells was evaluated by labelling with Annexin V (SigmaAldrich) as indicated by manufacture instructions.

Statistical analysis. Statistical data analysis was performed with IBM Statistical Package for Social Sciences-SPSS for Windows (version 20.0; IBM, Armonk, NY, USA). Chi-square analysis was used to compare categorical variables. Kaplan-Meier survival curves were used to evaluate correlation between glycans expression and RFS, logrank statistical test was used for curves comparison. Multiple Cox regression analysis was used to assess the effect of both antigens on the time to recurrence in BCG-treated patients and to adjust for potential confounders. Non-parametric Mann-Whitney test was used to compare the differences in the BCG attachment and internalisation to MCRnc and MCRsTn ${ }^{+}$cells.

\section{RESULTS}

Clinicopathological features and BCG treatment outcome. From the 94 cases evaluated, 36 had recurrence after BCG 
Table 1. Relation between patients clinical and tumour characteristics and response to BCG treatment and time to recurrence

\begin{tabular}{|c|c|c|c|c|c|c|}
\hline Variables & Total $\boldsymbol{n}(\%)$ & Responders $\boldsymbol{n}(\%)$ & Non-responders $\boldsymbol{n}(\%)$ & $P^{a}$ & HR $(95 \% \mathrm{Cl})$ & $P^{b}$ \\
\hline \multicolumn{7}{|c|}{ Age (years) } \\
\hline$<65$ & $51(54.3)$ & $37(63.8)$ & $14(38.9)$ & \multirow[t]{2}{*}{0.018} & 1.0 & \multirow[b]{2}{*}{0.005} \\
\hline$\geqslant 65$ & $43(45.7)$ & $21(36.2)$ & $22(61.1)$ & & $2.668(1.355-5.254)$ & \\
\hline \multicolumn{7}{|l|}{ Sex } \\
\hline Male & $78(83.0)$ & $47(81.0)$ & $31(86.1)$ & \multirow[t]{2}{*}{0.524} & 1.0 & \multirow[b]{2}{*}{0.798} \\
\hline Female & $16(17.0)$ & $11(19.0)$ & $5(13.9)$ & & $0.883(0.342-2.283)$ & \\
\hline \multicolumn{7}{|l|}{ Stage } \\
\hline $\mathrm{Ta}$ & $40(42.6)$ & $23(39.7)$ & $17(47.2)$ & \multirow[t]{2}{*}{0.471} & 1.0 & \multirow[b]{2}{*}{0.596} \\
\hline $\mathrm{T} 1$ & $54(57.4)$ & $35(60.3)$ & $19(52.8)$ & & $0.838(0.435-1.613)$ & \\
\hline \multicolumn{7}{|l|}{ Grade } \\
\hline Low & 38 (40.4) & 24 (41.4) & 14 (38.9) & \multirow[t]{2}{*}{0.843} & 1.0 & \multirow[b]{2}{*}{0.450} \\
\hline High & $56(59.6)$ & $34(58.6)$ & $22(61.1)$ & & $1.295(0.661-2.537)$ & \\
\hline \multicolumn{7}{|l|}{ Size $(\mathrm{cm})$} \\
\hline$<3$ & $62(66.7)$ & 38 (65.5) & 24 (68.6) & \multirow[t]{2}{*}{0.762} & 1.0 & \multirow[b]{2}{*}{0.513} \\
\hline$\geqslant 3$ & $31(33.3)$ & $20(34.5)$ & $11(31.4)$ & & $0.787(0.384-1.613)$ & \\
\hline \multicolumn{7}{|c|}{ Tumour number } \\
\hline Unifocal & $51(54.3)$ & $30(51.7)$ & $13(36.1)$ & \multirow[t]{2}{*}{0.140} & 1.0 & \multirow[b]{2}{*}{$0.04 c$} \\
\hline Multifocal & $43(45.7)$ & $28(48.3)$ & $23(63.9)$ & & $2.065(1.033-4.126)$ & \\
\hline \multicolumn{7}{|l|}{ CIS } \\
\hline No & $88(93.6)$ & $54(93.1)$ & $34(94.4)$ & \multirow[t]{2}{*}{1.000} & 1.0 & \multirow[b]{2}{*}{0.737} \\
\hline Yes & $6(6.4)$ & $4(6.9)$ & $2(5.6)$ & & $0.783(0.188-3.267)$ & \\
\hline \multicolumn{7}{|c|}{ Recurrence status } \\
\hline Primary & $48(51.0)$ & $31(53.4)$ & $17(47.2)$ & \multirow[t]{2}{*}{0.557} & 1.0 & \multirow[b]{2}{*}{0.401} \\
\hline Recurrent & $46(49)$ & $27(46.6)$ & $19(52.8)$ & & $1.327(0.686-2.564)$ & \\
\hline \multicolumn{7}{|c|}{ BCG schedule } \\
\hline$i B C G$ & $41(43.6)$ & $20(34.5)$ & $21(58.3)$ & \multirow[t]{2}{*}{0.023} & 1.0 & \multirow[b]{2}{*}{0.031} \\
\hline $\mathrm{mBCG}$ & $53(56.4)$ & $38(65.5)$ & $15(41.7)$ & & $0480(0.246-0.936)$ & \\
\hline $\begin{array}{l}\text { Abbreviations } \\
\text { Bold values in } \\
{ }^{\mathbf{a}} \text { Chi-square te } \\
{ }^{b} \text { Wald test. }\end{array}$ & $\begin{array}{l}=\text { Bacillus } C \\
P<0.05 .\end{array}$ & & & & & \\
\hline
\end{tabular}

treatment $(38.3 \%)$. The median follow-up time of the patients free of recurrence was 68.5 months (range: 6.0-135.0) and the median time of recurrence was 38.5 months (range: 10.0-122.0). The median follow-up time considering all the cases under analysis was 61.0 months (range: 6.0-135.0). Table 1 summarises patients and tumour clinicopathological features and its association with BCG response and RFS after treatment. We found that $61.1 \%$ of the nonresponders were over 65 years old at the time of tumour resection, whereas only $36.2 \%$ of responders were over 65 years old $(P=0.018)$. Furthermore, patients over 65 years have approximately three-fold increased risk of recurrence $(\mathrm{HR}=2.668$; $(1.344-5.254) ; P=0.005)$. Moreover, it was observed a higher percentage of patients treated only with iBCG in the non-responder group when compared with the responder group $(58.3 \%$ vs $34.5 \%, P=0.018)$. Therefore, patients treated with $\mathrm{mBCG}$ scheme showed a $52 \%$ reduced risk of recurrence $(\mathrm{HR}=0.480 ;(0.246-0.936) ; P=0.031)$. It was also found that patients with multifocal tumours had an increased risk of recurrence after BCG treatment $(\mathrm{HR}=2.065 ;(1.033-4.126) ; P=0.040)$. No association was found for other characteristics, such as gender, tumour stage, grade or size, CIS presence and prior recurrence.
Expression of sTn and s6T and association with clinicopathological features. Approximately $66 \%$ of the studied bladder tumours were sTn positive (Figure 1A and B) and in all cases the antigen was observed in more than $5 \%$ of the tumour area. Additionally, 10 out of $32 \mathrm{sTn}$ negative cases were positive for s6T (Figure 1C), which is structurally related to sTn. However, s6T assumed a more diffuse expression that did not exceed $5 \%$ of the tumour area in all cases.

The expression of sTn alone or in combination with s6T (sTn/s6T) was associated with high-grade tumours $(P=0.007 ; P=0.037$ Table 2$)$ and also with primary tumours $(P=0.001 ; P=0.039)$.

STn and sTn/s6T as predictors of BCG treatment outcome. sTn antigen was expressed by $74.1 \%$ of BCG responders and only by $47.2 \%$ of non-responders $(P=0.034$; Table 3$)$. When sTn and s6T were evaluated together, a similar relationship was observed $(P=0.0001$; Table 3).

From the 94 patients included in this study, 36 had recurrences after treatment and $75 \%$ of these tumour specimens were available for sTn and s6T screening. All non-responders who presented sTn- 
Table 2. Association between sTn and s6T antigens and clinicopathological characteristics

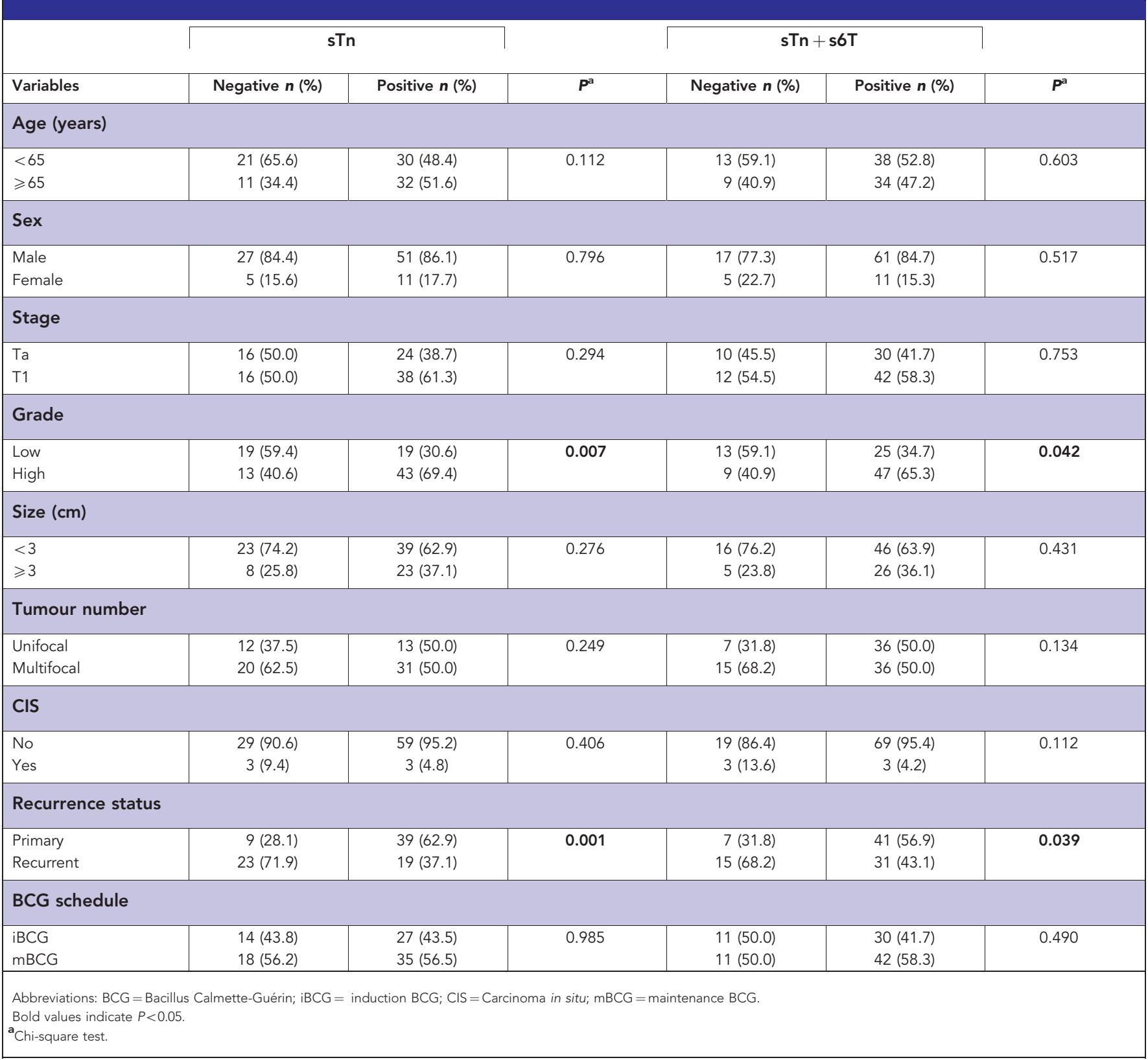

Table 3. STn and sTn/s6T frequencies and risk of recurrence after BCG therapy

\begin{tabular}{|c|c|c|c|}
\hline & Responders $\boldsymbol{n}(\%)$ & Non-responders $n$ (\%) & $\boldsymbol{P}$ value $^{a}$ \\
\hline \multicolumn{4}{|l|}{ sTn } \\
\hline Negative & $15(25.9)$ & $17(47.2)$ & \\
\hline Positive & $43(74.1)$ & $19(52.8)$ & 0.034 \\
\hline \multicolumn{4}{|c|}{ sTn and/or s6T } \\
\hline Negative & $6(10.5)$ & $16(43.2)$ & \\
\hline Positive & $51(89.5)$ & $21(56.8)$ & 0.0001 \\
\hline \multicolumn{4}{|c|}{$\begin{array}{l}\text { Abbreviation: BCG = Bacillus Calmette-Guérin. } \\
\text { ab Chi-square test. }\end{array}$} \\
\hline
\end{tabular}

negative tumours prior treatment had sTn-negative recurrences. From the 15 non-responder patients who had sTn-positive tumours, $40 \%$ presented sTn-negative recurrences.
Kaplan-Meier analysis was used to evaluate if sTn with or without s6T influenced the RFS after BCG treatment. No differences were found regarding sTn expression alone (Figure 2A). However, when sTn and s6T were considered together, significant differences were found $(P=0.001$; Figure 2B). Patients with sTn/s6T-positive tumours had higher RFS than negative tumours (100.1 vs 63.2 months).

A Cox regression analysis, adjusted to age, tumour number and treatment scheme, was performed to assess the individual effect of these antigens in recurrence after BCG. Patients with sTn-positive tumours presented a trend to a lower-risk recurrence after BCG $(\mathrm{HR}=0.544 ; 95 \% \mathrm{CI}$ : $(0.275-1.076) ; P=0.080$; Table 4). Likewise, cases positive for sTn/S6T showed a significant lower risk of recurrence $(\mathrm{HR}=0.296 ; 95 \% \mathrm{CI}:(0.148-0.594) ; P=0.001)$.

BCG interaction with MCRsTn $^{+}$cell line. To evaluate the affinity of BCG for cells expressing sTn, we set up in vitro assays with MCRnc and MCRsTn ${ }^{+}$cell lines, two genetically modified variants of the original MCR bladder cancer cell line. MCRnc cells 

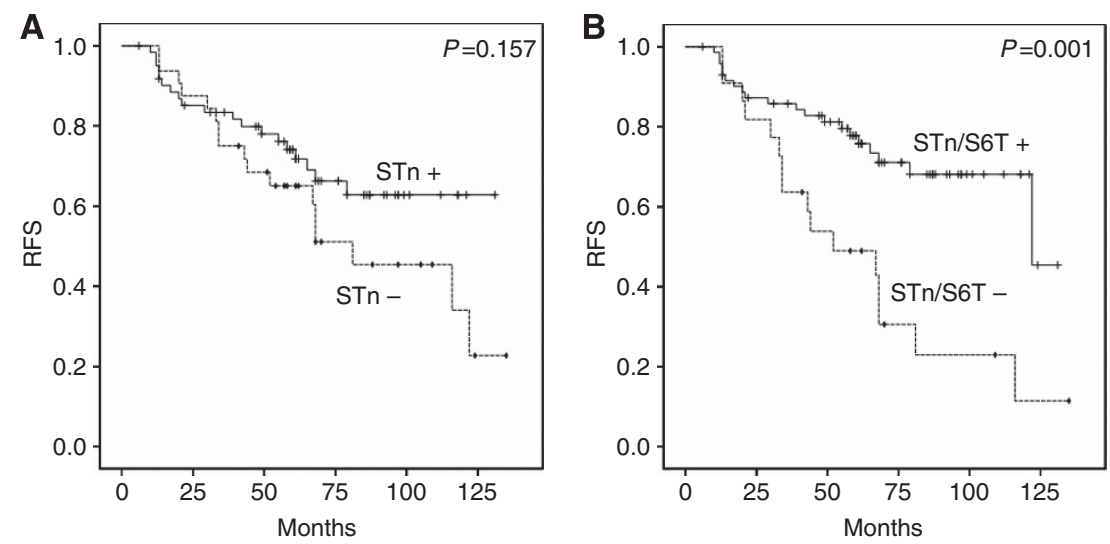

Figure 2. Effect of sTn and s6T expression in recurrence-free survival (RFS). Kaplan-Meier analysis to evaluate the association between RFS in the studied patients and: (A) sTn expression; (B) STn plus s6T presence (sTn/S6T). Comparison performed by log-rank test (A: $P=0.157 ; \mathbf{B}: P=0.001)$; \pm censored sTn or sTn/s6T-negative tumours; censored sTn or sTn/s6T-negative tumours.

\begin{tabular}{|c|c|c|c|}
\hline & $\mathrm{HR}^{\mathrm{a}}$ & $95 \% \mathrm{Cl}$ & $\boldsymbol{P}$ value \\
\hline \multicolumn{4}{|l|}{ sTn } \\
\hline $\begin{array}{l}\text { Negative } \\
\text { Positive }\end{array}$ & $\begin{array}{c}1.0 \\
0544\end{array}$ & $\begin{array}{c}\text { Referent } \\
0275-1.076\end{array}$ & 0.080 \\
\hline \multicolumn{4}{|c|}{$s T n+s 6 T$} \\
\hline $\begin{array}{l}\text { Negative } \\
\text { Positive }\end{array}$ & $\begin{array}{c}1.0 \\
0296\end{array}$ & $\begin{array}{c}\text { Referent } \\
0148-0.594\end{array}$ & 0.001 \\
\hline
\end{tabular}

Abbreviations: $\mathrm{BCG}=$ Bacillus Calmette-Guérin; $\mathrm{Cl}=$ confidence interval; $\mathrm{HR}=$ hazard ratio

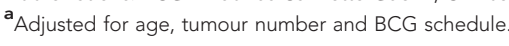

were transduced with an empty vector and MCRsTn ${ }^{+}$with the cDNA coding for the ST6GalNAc.I sialyltransferase. The phenotype of these transduced variants was previously described by Ferreira et al (2013). MCRsTn ${ }^{+}$presents a continuous and stable expression of the antigen sTn, whereas the MCRnc does not as shown in Supplementary Figure 1 (in the supplementary section).

$\mathrm{MCRsTn}^{+}$and its negative control MCRnc where then treated with BCG. Fluorescent-labelled BCG was internalised significantly over time, with a significant higher internalisation after $6 \mathrm{~h}$ incubation, when comparing with $2 \mathrm{~h}$ incubation (Figure $3 \mathrm{~A}$ ). Interestingly, after $6 \mathrm{~h}, \mathrm{MCRsTn}^{+}$cells showed a tendency to internalise higher amounts of BCG than MCRnc cells (Figure 4A and B). Small amounts of BCG are internalised, resulting in small shifts of FITC fluorescence of the cells after internalisation (Figure 4B).

We then evaluated apoptosis status in MCR cells after $6 \mathrm{~h}$ of BCG challenging, using Annexin V an earlier labelling marker for cells undergoing apoptosis. It was observed a consistent tendency for a higher cell death in MCRsTn ${ }^{+}$after BCG challenging (higher Annexin V labelling- $\mathrm{MFI}_{\mathrm{MCRnc}}=2560$ ) compared with MCRnc cells $\left(\mathrm{MFI}_{\mathrm{MCRsTn}+}=2640\right)$. In addition, a population of cells presenting stronger Annexin V labelling was also observed after $6 \mathrm{~h}$ BCG, which was higher (7\%) in MCRsTn ${ }^{+}$cell than MCRnc (4\%; Figure $4 \mathrm{~A})$. After a longer period of BCG challenging $(24 \mathrm{~h})$, MCRsTn ${ }^{+}$cells significantly decreased their size and granularity $\left(80 \%\right.$ of FSC $\left.^{\text {low }} S S C^{\text {low }}\right)$, which is usually typical of a rupture of plasma membrane and leakage of the cell's contents (Figure 4B). Conversely, MCRnc cells underwent little physical changes, presenting only $10 \%$ of FSC ${ }^{\text {low }} S C^{\text {low }}$ (Figure 4B). Furthermore, the internalisation of BCG by viable MCRsTn ${ }^{+}$cells at $24 \mathrm{~h}$ was markedly increased in relation to the controls (MCRnc; Supplementary Figure 2, supplementary section), therefore, in accordance with the observations made for $6 \mathrm{~h}$.

These results present evidence that both BCG internalisation and loss of cell viability are correlated and both features are enhanced in cells expressing sTn antigen. Altogether, these findings suggest that the bacillus acts more efficiently in cells expressing sTn probably due to its higher internalisation.

\section{DISCUSSION}

A significant percentage of high risk of recurrence/progression bladder tumours, conservatively treated with BCG immunotherapy after surgery, express cell-proteins yielding the sTn antigen (Ferreira et al, 2013). Despite the malignant potential of these tumours (Ferreira et al, 2013) and evidences that sTn expression may modulate the cell-BCG interaction (Clement et al, 2004; Julien et al, 2006; Pinho et al, 2007) as well as immune responses (Gilewski et al, 2007; Julien et al, 2009; Takamiya et al, 2013), nothing is known about the way patients exhibiting sTn-positive tumours respond to treatment.

We first observed that treatment outcome was influenced by age, treatment scheme and tumour multifocallity, as showed in other reports (Bohle and Bock, 2004; Joudi et al, 2006; Fernandez-Gomez et al, 2008; Malmstrom et al, 2009; Kohjimoto et al, 2010; Ajili et al, 2012). To overcome the samples heterogeneity, these variables were taken into account in multivariate analysis models to assess the influence of tumour-associated glycans in BCG response.

We also found that sTn expression was associated with highgrade tumours, which is in agreement with our previous observations (Ferreira et al, 2013). STn expression was also associated with primary tumours. However, this may result from fact that the percentage of high-grade tumours was much higher among primary cases (90\%) than in recurrences (67\%). Altogether, these data reinforce the notion that sTn is a surrogate marker of high-risk bladder cancer.

Furthermore, we report for the first time that bladder tumours express the sTn-related carbohydrate antigen s6T. From the structural point of view, s6T may be considered a form of the sTn antigen masked by a Gal residue $O-3$ linked to the GalNAc moiety. To our knowledge, s6T has only been observed in human cancer cell lines (Marcos et al, 2004; Julien et al, 2006; Pinho et al, 2007). We also describe that the incubation of tissue 

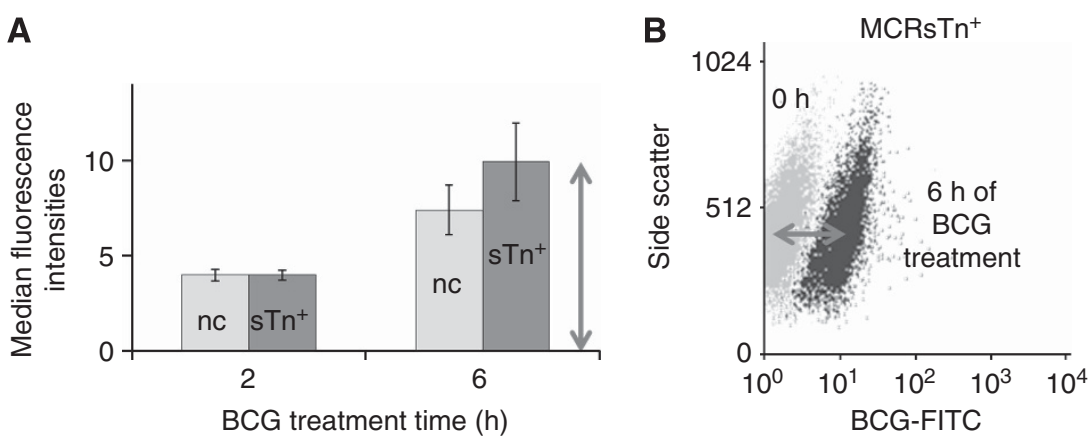

Figure 3. BCG internalisation by bladder cancer cell lines over time. (A) Internalisation of fluorescent-labelled BCG by mock-transduced MCRnc cells (light grey bars) and by ST6GalNAc. I-transduced MCRsTn ${ }^{+}$cells (dark grey bars), after 2 or $6 \mathrm{~h}$ of exposure with BCG. An obvious timedependent internalisation was observed, and a tendency for higher fluorescent-labelled BCG internalisation rates was observed by MCRsTn ${ }^{+}$ cells. Data are the average of three independent experiments (mean fluorescence intensity). (B) A representative flow cytometry dot plots of $\mathrm{MCRsTn}^{+}$cells before (light grey dots) and after $6 \mathrm{~h}$ (dark grey dots) of fluorescent-labelled BCG exposure. Horizontal and transversal double sense arrows represent the MFI shift observed after $6 \mathrm{~h}$ of BCG internalisation.

A

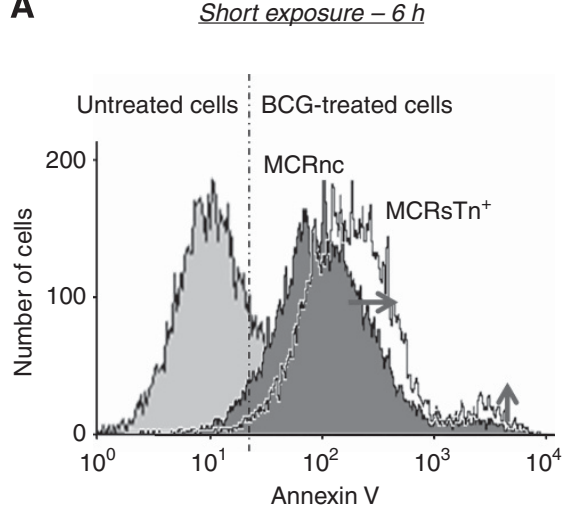

B

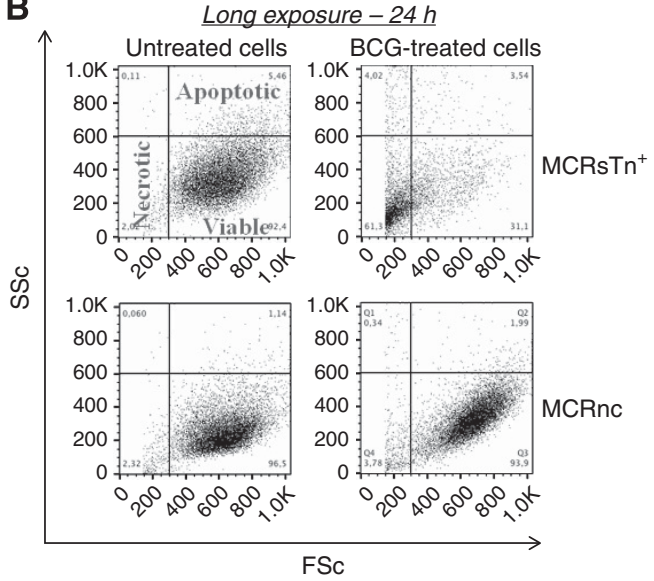

Figure 4. Effect of BCG in the viability of bladder cancer cell lines expressing sTn. (A) The apoptotic status of MCR cell lines was evaluated after $6 \mathrm{~h}$ exposure to BCG, by Annexin $\mathrm{V}$ staining and flow cytometry analysis. Flow cytometry histograms show $\mathrm{MCRnc}$ and $\mathrm{MCRs}^{+}{ }^{+}$cells labelled with Annexin $\vee$ before (light grey histograms) and after $6 \mathrm{~h}$ of BCG treatment (dark grey and open histograms, respectively). MCRsTn ${ }^{+}$cells showed higher Annexin $\mathrm{V}$ labelling (MFI $\mathrm{MCRnc}_{2}=2560$ to $\mathrm{MFI}_{\mathrm{MCRsTn}+}=2640$-horizontal arrow) and a higher percentage of cells with strong Annexin V labelling (4\% to 7\%-vertical arrow). (B) Analysis of size and granularity of cells exposed $24 \mathrm{~h}$ to BCG. Dot plot analysis of BCG-treated $\mathrm{MCRsTn}^{+}$revealed a marked decrease of both side-angle light scatter (SSc) and forward-angle light scatter (FSc) signals, which is consistent with massive cell death. By contrast, BCG treatment resulted in little changes of the dot plot pattern of MCRnc cells. Data are from one representative assay out of three independent experiments.

sections with a $\beta$-(1-3)-galactosidase removed the $O$-3-linked Gal residue exposing the sTn antigen, allowing its detection by immunohistochemistry with the same antibody used for sTn without significant time consumption. This approach may now be applied to estimate s6T expression in other solid tumours. Studies in vitro studies have shown that s6T expression influences tumour microenvironment similarly to sTn (Pinho et al, 2007). Therefore, both antigens were evaluated in the context of BCG immune response.

STn expression alone or in combination with that of s6T was associated with lower recurrence rates after BCG. Furthermore, patients expressing sTn and/or s6T presented longer RFS and these antigens were found to be independent predictive markers of reduced recurrence after BCG immunotherapy. Moreover, recurrences after treatment displayed a reduced expression of sTn antigens suggesting that BCG may be more effective against cells expressing these glycans. Thus, sTn-like $O$-glycans should be considered in a biomarker panel directed to predict BCG treatment outcome.
STn-expressing cells presented enhanced capacity for BCG adhesion and internalisation and higher BCG-mediated cell death in vitro. This strongly suggests that sTn expression favours BCGmediated elimination of tumour cells, which may, in part, explain the high correlation between these glycans and treatment response. The exact mechanism underlying these observations remains unknown. However, BCG is known to bind fibronectin- $\alpha 5 \beta 1$ integrin complexes promoting a rearrangement of cytoskeletal actin in host cells, which results in the phagocytosis of the pathogen (Chen et al, 2003; Alexandroff et al, 2010). Clement et al (2004) described that integrin $\beta 1$ chains express sTn and that the antigen enhanced integrin-fibronectin adhesion. Thus, sTn may contribute to a more efficient binding of the bacillus to tumour cells and consequently a better response to BCG. The bacillus may also directly target cells in a fibronectin-independent manner (Schneider et al, 1994), namely by binding sTn or specific carbohydrates residues such as $\alpha 2,6$ sialic acids. On the other hand, sTn is a product of incomplete $O$-glycosylation of proteins (Dall'Olio et al, 2012), a reduction in the structural complexity of 
O-glycan may allow the bacillus to bind more efficiently to tumour cells. The expression of sTn also induces profound morphological changes in tumour cells (Clement et al, 2004; Pinho et al, 2007) that may further contribute to the bacillus attachment. A deeper understanding of these phenomena may provide new insights on the mechanism of action of BCG and ways to improve the therapeutics.

The efficiency of BCG therapy among sTn-positive tumours may also be related with the immunogenic properties of the antigen (Gilewski et al, 2007; Julien et al, 2009; Takamiya et al, 2013). sTn-based vaccines elicit strong immune responses against breast, ovarian and colorectal cancers in animal models (Gilewski et al, 2007; Julien et al, 2009). Still, using BCG as an immunologic adjuvant was considered essential for the development of both humoral and cellular immune responses against sTn (Miles et al, 1996; O’Boyle et al, 2006). Similarly, instillations with BCG may be enhancing immune responses against these tumour-associated glycans. On the other hand, we observed a higher internalisation of BCG by sTn-expressing cells. After BCG internalisation, malignant cells often act as antigen-presenting cells contributing to the immunologic cascade that leads to tumour clearance (Ratliff, 1992; Alexandroff et al, 2010). Therefore, one may also hypothesise that the expression of this particular glycan may increase the probability of generating BCG antigen-presenting cells in the tumour niche. Understanding these events may allow developing alternative carbohydrate-based immunotherapies for bladder cancer and should be addressed in future studies.

Although this is a retrospective study involving a limited number of cases, our results strongly suggest that BCG immunotherapy is efficient against sTn-positive tumours. Even though we have not determined the exact mechanisms underlying this event, we demonstrated that BCG adhesion and internalisation is higher for sTn-positive cells in vitro, further reinforcing tumour findings.

In conclusion, it has been demonstrated that sTn and s6T antigens correlated with a better response to this treatment. These glycans, in association with other BCG response-associated molecules, may allow the establishment of a predictive panel that can guide therapeutic decision.

\section{ACKNOWLEDGEMENTS}

This work was supported by Portuguese Foundation for Science and Technology (FCT) Postdoctoral grant SFRH/BPD/66288/ 2009 (José Alexandre Ferreira), $\mathrm{PhD}$ grants SFRH/BD/ 43399/2008 (Luis Lima), SFRH/BD/81860/2011 (Mariana Silva), SFRH/BD/45120/2008 (Paulo F. Severino). FCT is co-financed by European Social Fund (ESF) under Human Potential Operation Programme (POPH) from National Strategic Reference Framework (NSRF).

\section{CONFLICT OF INTEREST}

The authors declare no conflict of interest.

\section{REFERENCES}

Ajili F, Manai M, Darouiche A, Chebil M, Boubaker S (2012) Tumor multiplicity is an independent prognostic factor of non-muscle-invasive bladder cancer treated with Bacillus Calmette-Guerin immunotherapy. Ultrastruct Pathol 36(5): 320-324.

Alexandroff AB, Nicholson S, Patel PM, Jackson AM (2010) Recent advances in bacillus Calmette-Guerin immunotherapy in bladder cancer. Immunotherapy 2(4): 551-560.
Babjuk M, Oosterlinck W, Sylvester R, Kaasinen E, Bohle A, Palou-Redorta J, Roupret M (2011) EAU guidelines on non-muscle-invasive urothelial carcinoma of the bladder, the 2011 update. Eur Urol 59(6): 997-1008.

Becich MJ, Carroll S, Ratliff TL (1991) Internalization of bacille CalmetteGuerin by bladder tumor cells. J Urol 145(6): 1316-1324.

Bohle A, Bock PR (2004) Intravesical bacille Calmette-Guerin versus mitomycin $\mathrm{C}$ in superficial bladder cancer: formal meta-analysis of comparative studies on tumor progression. Urology 63(4): 682-686.

Chen F, Zhang G, Iwamoto Y, See WA (2003) Bacillus Calmette-Guerin initiates intracellular signaling in a transitional carcinoma cell line by cross-linking alpha 5 beta 1 integrin. J Urol 170(2 Pt 1): 605-610.

Clement M, Rocher J, Loirand G, Le PJ (2004) Expression of sialyl-Tn epitopes on beta1 integrin alters epithelial cell phenotype, proliferation and haptotaxis. J Cell Sci 117(Pt 21): 5059-5069.

Dall'Olio F, Malagolini N, Trinchera M, Chiricolo M (2012) Mechanisms of cancer-associated glycosylation changes. Front Biosci 17: 670-699.

Fernandez-Gomez J, Solsona E, Unda M, Martinez-Pineiro L, Gonzalez M, Hernandez R, Madero R, Ojea A, Pertusa C, Rodriguez-Molina J, Camacho JE, Isorna S, Rabadan M, Astobieta A, Montesinos M, Muntanola P, Gimeno A, Blas M, Martinez-Pineiro JA. Club Urologico Espanol de Tratamiento O (2008) Prognostic factors in patients with non-muscle-invasive bladder cancer treated with bacillus CalmetteGuerin: multivariate analysis of data from four randomized CUETO trials. Eur Urol 53(5): 992-1001.

Ferreira JA, Videira PA, Lima L, Pereira S, Silva M, Carrascal M, Severino PF, Fernandes E, Almeida A, Costa C, Vitorino R, Amaro T, Oliveira MJ, Reis CA, Dall'Olio F, Amado F, Santos LL (2013) Overexpression of tumour-associated carbohydrate antigen sialyl-Tn in advanced bladder tumours. Mol Oncol 7(3): 719-731.

Gilewski TA, Ragupathi G, Dickler M, Powell S, Bhuta S, Panageas K, Koganty RR, Chin-Eng J, Hudis C, Norton L, Houghton AN, Livingston PO (2007) Immunization of high-risk breast cancer patients with clustered sTn-KLH conjugate plus the immunologic adjuvant QS-21. Clin Cancer Res 13(10): 2977-2985.

Joudi FN, Smith BJ, O’Donnell MA, Konety BR (2006) The impact of age on the response of patients with superficial bladder cancer to intravesical immunotherapy. J Urol 175(5): 1634-1639.

Julien S, Adriaenssens E, Ottenberg K, Furlan A, Courtand G, Vercoutter-Edouart AS, Hanisch FG, Delannoy P, Le BX (2006) ST6GalNAc I expression in MDA-MB-231 breast cancer cells greatly modifies their O-glycosylation pattern and enhances their tumourigenicity. Glycobiology 16(1): 54-64.

Julien S, Picco G, Sewell R, Vercoutter-Edouart AS, Tarp M, Miles D, Clausen H, Taylor-Papadimitriou J, Burchell JM (2009) Sialyl-Tn vaccine induces antibody-mediated tumour protection in a relevant murine model. Br J Cancer 100(11): 1746-1754.

Kohjimoto Y, Iba A, Shintani Y, Inagaki T, Uekado Y, Hara I (2010) Impact of patient age on outcome following bladder-preserving treatment for nonmuscle-invasive bladder cancer. World J Urol 28(4): 425-430.

Lima L, Dinis-Ribeiro M, Longatto-Filho A, Santos L (2012) Predictive biomarkers of bacillus calmette-guerin immunotherapy response in bladder cancer: where are we now? Adv Urol 2012: 232609.

Malmstrom PU, Sylvester RJ, Crawford DE, Friedrich M, Krege S, Rintala E, Solsona E, Di Stasi SM, Witjes JA (2009) An individual patient data metaanalysis of the long-term outcome of randomised studies comparing intravesical mitomycin $\mathrm{C}$ versus bacillus Calmette-Guerin for non-muscleinvasive bladder cancer. Eur Urol 56(2): 247-256.

Marcos NT, Pinho S, Grandela C, Cruz A, Samyn-Petit B, Harduin-Lepers A, Almeida R, Silva F, Morais V, Costa J, Kihlberg J, Clausen H, Reis CA (2004) Role of the human ST6GalNAc-I and ST6GalNAc-II in the synthesis of the cancer-associated sialyl-Tn antigen. Cancer Res 64(19): 7050-7057.

Miles DW, Towlson KE, Graham R, Reddish M, Longenecker BM, Taylor-Papadimitriou J, Rubens RD (1996) A randomised phase II study of sialyl-Tn and DETOX-B adjuvant with or without cyclophosphamide pretreatment for the active specific immunotherapy of breast cancer. Br J Cancer 74(8): 1292-1296.

O'Boyle KP, Coatsworth S, Anthony G, Ramirez M, Greenwald E, Kaleya R, Steinberg JJ, Dutcher JP, Wiernik PH (2006) Effects of desialylation of ovine submaxillary gland mucin (OSM) on humoral and cellular immune responses to Tn and sialylated Tn. Cancer Immunity 6: 5.

Ohno S, Ohno Y, Nakada H, Suzuki N, Soma G, Inoue M (2006) Expression of Tn and sialyl-Tn antigens in endometrial cancer: its relationship with 
tumor-produced cyclooxygenase-2, tumor-infiltrated lymphocytes and patient prognosis. Anticancer Res 26(6A): 4047-4053.

Oosterlinck W, van der Meijden A, Sylvester R, Böhle A, Rintala E, Solsona Narvón E, Lobel B (2006) Guidelines on TaT1 (Non-muscle invasive) Bladder Cancer. In EAU Guidelines 2006, Office EG (ed). EAU Guidelines Office: Arnhem, The Netherlands.

Palou Redorta J (2006) Management of BCG 'Failures'. Eur Urol 49(5): 779-780.

Pinho S, Marcos NT, Ferreira B, Carvalho AS, Oliveira MJ, Santos-Silva F, Harduin-Lepers A, Reis CA (2007) Biological significance of cancerassociated sialyl-Tn antigen: modulation of malignant phenotype in gastric carcinoma cells. Cancer Lett 249(2): 157-170.

Ratliff TL (1992) Role of the immune response in BCG for bladder cancer. Eur Urol 21(Suppl 2): 17-21.

Schneider B, Thanhauser A, Jocham D, Loppnow H, Vollmer E, Galle J, Flad HD, Ulmer AJ, Bohle A (1994) Specific binding of bacillus CalmetteGuerin to urothelial tumor cells in vitro. World J Urol 12 6: 337-344.

Sinn HW, Elzey BD, Jensen RJ, Zhao X, Zhao W, Ratliff TL (2008) The fibronectin attachment protein of bacillus Calmette-Guerin (BCG) mediates antitumor activity. Cancer Immunol Immunother 57(4): 573-579.
Takamiya R, Ohtsubo K, Takamatsu S, Taniguchi N, Angata T (2013) The interaction between Siglec-15 and tumor-associated sialyl-Tn antigen enhances TGF-beta secretion from monocytes/macrophages through the DAP12-Syk pathway. Glycobiology 23(2): 178-187.

van Rhijn BW, Burger M, Lotan Y, Solsona E, Stief CG, Sylvester RJ, Witjes JA, Zlotta AR (2009) Recurrence and progression of disease in non-muscle-invasive bladder cancer: from epidemiology to treatment strategy. Eur Urol 56 3: 430-442.

Videira PA, Correia M, Malagolini N, Crespo HJ, Ligeiro D, Calais FM, Trindade H, Dall'Olio F (2009) ST3Gal.I sialyltransferase relevance in bladder cancer tissues and cell lines. BMC Cancer 9: 357.

Zuiverloon TC, Nieuweboer AJ, Vekony H, Kirkels WJ, Bangma CH, Zwarthoff EC (2012) Markers predicting response to bacillus CalmetteGuerin immunotherapy in high-risk bladder cancer patients: a systematic review. Eur Urol 61(1): 128-145.

This work is published under the standard license to publish agreement. After 12 months the work will become freely available and the license terms will switch to a Creative Commons AttributionNonCommercial-Share Alike 3.0 Unported License.

Supplementary Information accompanies this paper on British Journal of Cancer website (http://www.nature.com/bjc) 